\title{
The mental health of the Ukrainian nation as a driving force for economic growth
}

\author{
Alona Deriabina \\ Independent researcher, Mental Health Division NPA, Kyiv, Ukraine
}

\begin{abstract}
Introduction: Achieving a high level of social welfare requires investment in human capital, and its sufficiency and rational use is a necessary condition for the development of the state. The health of the nation as a factor of state formation and security of the state is a basic component of human capital and competitiveness of the country and is closely integrated with the economy, science, and defense.

Purpose: The purpose of our study is the system of protection and preservation of the mental health of Ukrainians, in the framework and context of economic development.

Methodology: The study was conducted based on statistical data of the Center for Medical Statistics of the Ministry of Health of Ukraine for the period 2016-2020. The following methods were used: analytical, medical statistics, comparative analysis, system approach.

Results: The incidence and prevalence of mental and behavioral disorders among the entire population of Ukraine, as well as among the adult population, working-age and old age, depending on the place of residence and sex, were studied and analyzed.

Conclusions: The problems of the current state of mental health of Ukrainians are studied and the ways of solving these problems are suggested. The retrospective dynamics of the dependence of the level of psychological health of the population and economic development of the country are analyzed. The tendencies of prevention and improvement of the level of public awareness about the role of mental health on the example of the leading countries of the world are analyzed.
\end{abstract}

\section{Keywords}

mental health, mental and behavioral disorders, protective factors, risk factors, human capital, national health, state security, economic development.

Address for correspondence:

Alona Deriabina

e-mail: alyonaderiabina.27@gmail.com

This work is licensed under a Creative Commons Attribution-

Submitted for publication: 03 NonCommercial 4.0 International License (CC BY-NC 4.0).

\section{Introduction}

Mental health is the foundation of a nation's prosperity, as in any democratic society, citizens play a major role in the development of a nation.
Mental health cannot be limited to just being defined as the absence of mental illness or disorder. It is an all- encompassing concept of the psychological well-being of people. If a country wants to develop economically, its citizens must 
have an appropriate psychological reserve. Citizens need to be mentally healthy to participate in activities such as leadership elections, working, family management, communication, outside of daily activities. These requirements can be too complex for people and can be stressful if the country's mental health system is weak. Governments should develop mental health services that are accessible, appropriate and nondiscriminatory with a moral and political point of view.

Over the 30 years of Ukraine's independence, public interest in mental health issues has increased, and certain reforms have begun. In January 2020, Ukraine was selected as a priority country for the World Health Organization's (WHO) Special Initiative for Mental Health (2019-2023). The Ministry of Health sought to use funding and technical support provided by the WHO Special Initiative to complete and operationalize the Mental Health Plan. The plan emphasizes the need to raise awareness of mental health, combat discrimination and human rights violations of persons with mental health problems, increase access to health care through deinstitutionalization and development of services at the community level, and improve the professional competence of health personnel.

since joining the initiative, Ukraine has experienced renewed political commitment to mental health policies and the expansion of mental health services. In turn, Ukraine's GDP growth rate averaged 0.04 percent between 2010 and 2021 and the country experienced faster economic growth. However, once the government was ready to move on to a new phase of health care reform in April 2020, the national focus shifted due to a change in government leadership. More importantly, the acceleration of the COVID-19 pandemic has dramatically changed the priorities of the healthcare system.

Thus, mental disorders remain the second leading cause of the burden of disability in the country in terms of disability-adjusted life years and is estimated to affect $30 \%$ of the population. According to the World Health Organization in Ukraine, more than 1.6 million citizens are registered at psychiatric and narcological clinics and units nationwide. Only last year, about 185,000 of Ukrainians were diagnosed with mental health conditions and disorders. However, most people affected may not seek help at all due to lack of trust in the old system, stigma and other barriers. This has a significant impact on economic development as people continue to suffer from mental health problems and are unable to live fulfilling lives. Stigma, discrimination and human rights violations are still widespread. Consequently, the transformation and improvement of the mental health care system in Ukraine is necessary as well as following the best practices of European countries and their adaptation to the mentality.

\section{Design/Methodology/Approach}

The study was conducted based on statistical data of the Center for Medical Statistics of the Ministry of Health of Ukraine for the period 20162020. The following methods were used: analytical, medical statistics, comparative analysis, system approach.

\section{Results and discussion}

If we look at the correlation between the level of income of countries and mortality, then the connection can be traced directly: the richer the country, the lower the mortality rate and the higher the life expectancy. This relationship was shown back in 1996 by Lent Pritchett (World Bank) and Larry Summers (later the US Treasury Secretary and Economic Advisor in the Barack Obama administration), and it still does not change - so it is observed in the data for 2018-2020 biennium But while we see a positive correlation between the gross domestic product and life expectancy in the data, it does not imply a causal relationship. Indeed, for example, not only an increase in GDP can lead to an improvement in the health of citizens, but an improvement in the health of a nation can lead to economic growth.

The easiest way to show causality is to look at exogenous shocks (or, as economists say, use natural experimentation) affecting either health or GDP and income, and assess how these shocks will indirectly affect other indicators.

Looking at the impact of health on economic growth, there are several historical examples. For example, the John Bates Clark Medal winner Daron Acemoglu and his co-author, MIT Professor Simon Johnson, showed that the invention and widespread use of antibiotics in the 1930s - 1940s. led to an increase in life expectancy and a decrease in mortality, but did not greatly affect the change in GDP. On the other hand, Professor Jeffrey Sachs and his co-author John Luc Gallup (Harvard) have demonstrated that aggressive malaria control in sub-Saharan Africa would lead to GDP growth in this area by about $2.6 \%$ per year.

But another relationship is no less interesting: how can a drop in income affect health? Here, natural experiments for analysis are the previous 
economic recessions and crises, which occurred with enviable regularity in all parts of the world.

Over the past twenty years, several studies have separately analyzed the impact of recessions and crises on mortality. (Romash, Vynnyk, 2019) However, their findings are heterogeneous and differ significantly for developed and developing countries. One of the most famous studies in this area was a series of works by Christopher Room of the University of Virginia, published in the early 2000s. Rum showed that in the United States in the last quarter of the twentieth century, the rate of increase in mortality decreased along with the rate of economic growth. During the recession, people gave up many bad habits. As a result, mortality from a group of diseases caused by the consequences of smoking and being overweight, as well as from cardiovascular and some other diseases, decreased, reducing overall mortality. Later work found a similar effect.

However, other studies in recent years have not found a significant correlation between mortality and recessions in developed countries. So, the same Rum in a later work, in which he expanded the period of analysis of his previous studies, showed that now, on new data, up to 2010, there is no longer a negative relationship between mortality and recessions. Similar results were also obtained in the work of the 2019 Nobel laureates Abhijit Banerjee and Esther Duflo et al, which used data on the income and health of the population of France in the late 19th and early 20th centuries.

In contrast to developed countries, in developing economies and especially in rather poor countries, during economic crises and recessions, there is often an increase in mortality. There are several mechanisms to explain this phenomenon.

First, as a rule, crises hit developing countries much harder than developed ones. In them, the GDP is shrinking more, and the incomes of the population and living standards are falling more, and poverty is growing more. Secondly, the health of the population can be threatened due to the low level of social protection and medical support, as well as credit restrictions, lack of savings among the poor, which impede the ability to smooth out economic shocks: as a result, a deterioration in the quality of nutrition, low attention to preventive health services; and the lack of funds for medicines and health care payments by the poor.

All this in times of crisis leads to an increase in mortality. In addition, the deterioration of medical care due to a shortage of staff and a decrease in public spending on the health care system in particularly severe economic downturns also lead to an increase in mortality during recessions and crises.

According to the survey, $2.3 \%$ of Ukrainians in 2020 suffered from mental and behavioral disorders - 1,706,070 people (prevalence - 3989.9 per 100 thousand of the total population, compared to 2019, this figure decreased by 0.2 $\%)$. The primary morbidity of the entire population of the country remained at almost the same level: growth in 2020 by $0.06 \%$ compared to 2019 (2020 - 319.0 per 100 thousand of the total population; in 2019 - 318.8). The prevalence of mental and behavioral disorders was higher among rural residents (4358.3 per 100 thousand of the population) than among urban residents (3823.1), by $14 \%$ (this trend continued in previous years). It should also be noted that the prevalence in rural areas tended to increase in 2020 by $0.3 \%$ compared to 2019. In contrast to the prevalence, the incidence of mental and behavioral disorders was higher among urban residents (324.5 per 100 thousand of the corresponding population) than among rural (306.7), by $5.8 \%$, and also the incidence rates of city residents tended to increase compared to 2014 by $1.2 \%$ (2019 - 320.7 by 100 thousand population, $2020-324.5$ ). This is most likely due to better access to health care for city residents.

In the structure of the prevalence of diseases of the adult population (18 years and older), the share of mental and behavioral disorders in 2020 was $2.5 \%$ (4280.7 per 100 thousand adults) and tended to increase compared to 2019 by $0.1 \%$ (2019 - 4276.8 per 100 thousand), the primary incidence remained at the same level (295.3 per 100 thousand adults). At the same time, in rural areas the prevalence (4847.8 per 100 thousand of the corresponding population) and primary morbidity (304.4 per 100 thousand) were higher than similar indicators among the urban population (4032.4 and 291.3 per 100 thousand). Among the adult male population of the country, mental and behavioral disorders also prevailed over women (men: prevalence - 6046.2 and morbidity - 380.2 per 100 thousand of the population; women: prevalence - 2826.8; morbidity - 225.4).

In 2020, mental and behavioral disorders made an even greater contribution to the structure of the prevalence of diseases among the working population $-3.55 \%$. Thus, in the structure of the prevalence of diseases of the most economically active, productive part of the population, the share of mental and behavioral disorders was higher than in the structures among the total population, adults and the population older than working age, in addition to the prevalence and

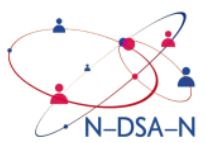


primary morbidity tended to increase. In 2020, the prevalence increased compared to 2019 by $0.25 \%$ (2019 - 4795.7 per 100 thousand working population; 2020 - 4807.7). Primary morbidity also tended to increase by 0.69\% (2019 - 331.7 per 100 thousand; 2020 - 334.0).

For comparison, we present data on the mental health of the population of Europe. According to the WHO (2017), 27\% of the adult population of the European Union, Iceland, Norway and Switzerland between the ages of 18 and 65 had at least one mental disorder last year (including problems related to the use of psychoactive substances, psychosis, depression, anxiety and eating disorders). This is a large number (at least 83 million people) of human loss from ill health, but it is incomplete because it does not include people over 65 years of age. In addition, psychoneurological disorders are the third leading cause of loss of life due to DALY (Disability-adjusted life year) in Europe, accounting for $15.2 \%$ of cardiovascular disease $(26.6 \%)$ and malignancies. (cancer) - 15.4\%. Three of the fifteen leading diseases that account for the burden of illness (DALY) are mental disorders, namely: unipolar depressive disorders are the third leading cause (3.8\% of all DALYs); disorders caused by alcohol consumption - sixth $(2.9 \% 3.8 \%$ of all DALYS); Alzheimer's disease and other dementias are the fifteenth cause of DALYs $1.9 \%$ of all DALYS). In most countries of the European Union, $35-45 \%$ of absenteeism is due to mental health problems. In addition, mental disorders make the largest contribution to the chronic pathology of the EP population. According to the WHO, psychoneurological disorders rank first among the diseases of the European population by years of disability (YLD), which is $36.1 \%$ of all chronic diseases. The proportion of depressive disorders is $11-15 \%$ of all YLDs, which rank first, becoming the leading chronic disease in Europe; Alcohol-related mental disorders rank third in Europe (6.4\% of all YLDs); anxiety disorders - sixth (4\% of all YLDs), Alzheimer's disease and other dementias - ninth ( $3 \%$ of all YLDs); migraine is eleventh $(2.7 \%)$, schizophrenia is fifteenth (1.8\%), and bipolar disorder is seventeenth $(1.6 \%$ of all YLDs) $[4,5,7,8]$.

The level of a person's mental health at any given time is determined by several social, psychological, and biological factors. The main determinants of the growing number of mental disorders in the modern world and according to research: population density, urbanization, destruction of the environment, the complexity of production and educational technologies, increasing information pressure, increasing the frequency of emergencies (emergencies), including hostilities, deterioration of physical health (including reproductive), increase in the number of brain injuries and birth injuries, intensive aging of the population (Romash,2020). Mental health is also affected by socio-cultural trends: weakening of family and neighborly ties and mutual assistance; a sense of alienation from state power and the system of government; growth of material needs of "consumer" society; the spread of sexual freedom; rapid increase in social and geographical mobility. The most vulnerable in terms of predisposition to mental disorders are groups that are in an unfavorable life situation and the least provided with resources.

The impact of economic downturns on mental health should also be addressed, as any economic crisis is a very dangerous period for the mental health of both the general population and those directly affected by the crisis, during which the prevalence of mental disorders, drunkenness, suicide and deaths from alcohol abuse is increasing. Therefore, the governments of all civilized countries need to improve mental health measures. The economic crisis and the state of mind of the population are closely linked, ie the worse the economic situation, the worse the state of mental health. The economic consequences of mental disorders (expressed mainly in the form of reduced productivity) for the European Union are estimated at $3-4 \%$ of gross national product. Because serious mental disorders often begin in adolescence or adolescence, decreased productivity can be long-lasting. In the countries of the WHO European Region, mental disorders account for more than a third of all man-years lost due to disability (33\%). Thus, economic distress affects the factors that determine mental health, resulting in weakening protective factors and increasing risk factors. The mental health of the working-age population is favorably affected by employment guarantees, the ability to manage one's work, and social support at work. On the contrary, financial difficulties (poverty) and social isolation are the main socio-economic risk factors for mental disorders. As an example, in the European Union, rising unemployment has increased alcohol abuse mortality by $28 \%$. Thus, the economic crisis harms the health of the population, especially mental health, so the degree of impact of the economic crisis on the mental health of the population depends on political decisions. According to the WHO, the adverse effects of the crisis on mental health are counteracted by active labor market programs, as well as measures to support families, limit the 
availability of alcohol, debt relief programs, and universal access to mental health services.

In countries with well-developed social protection systems, economic decline has less of an impact on mental health. Data from Europe show that the economic crisis does not always exacerbate the health gap between different segments of the population. Governments need to focus on the priority needs of the most vulnerable, ensuring a high level of coverage for the poorest and supporting families at risk. An example is the dynamics of suicides in Sweden and Spain in 1980-2005. In the early 1990s, Sweden experienced a severe banking crisis, which led to a very rapid rise in unemployment, but the suicide rate during this time not only did not rise but even steadily decreased. The situation is different in Spain, which experienced some banking crises in the 1970s and 1980s. As unemployment increased, the number of suicides increased, but when the unemployment rate decreased, the number of suicides decreased. Although there are many differences between Sweden and Spain, the main ones are the number of resources allocated to the social protection budget: family support, unemployment benefits, and health care. Thus, supporting social security at the state level can increase the resilience of communities in the face of economic shocks and reduce the impact that unemployment and the stress of economic decline have on mental health.

Current research shows that the impact of the economic crisis on mental health can be reduced by acting in five main areas: 1 . Active labor market programs. 2. Family support programs. 3. Control over alcohol prices and their availability. 4. Primary care for people at increased risk of mental disorders. 5. Debt relief programs [6].

In most countries, especially low- and middleincome countries, mental health services are severely underfunded, both in terms of human and financial resources. Most of the available health resources are currently spent on specialized treatment and care for the mentally ill, and a minority on the integrated mental health system. Instead of providing care in the country's major psychiatric hospitals, mental health care should be integrated into primary health care, general care should be provided in general hospitals, and community-based mental health services should be developed.

Mental health promotion is one of the leading challenges of today and includes many actions to ensure respect for and protection of fundamental civil, political, socio-economic, and cultural human rights, which is the basis for mental health promotion, in the absence of security and freedom to maintain a high level. mental health is very difficult. Given that the mental health of the population is influenced by many factors that are outside the health sector in the traditional sense, it is governments that can provide and influence many of these factors at the political level, but we must not forget that The direction of public policy can have both positive and negative effects on the mental health of the population, so it should not be ignored and it is necessary to calculate the impact of changes in social and economic policy on mental health. Socio-economic factors are closely interlinked, and policy changes within one sector have a cascading effect on other sectors, so it is advisable to monitor the impact of changes in economic and social policies on the mental health of the population. The state should pursue a national policy on mental health care with a focus not only on mental disorders but also on the broader aspects that contribute to the promotion of mental health. This should be taken into account in the strategies and programs of the public and private sectors, which should be comprehensive and multisectoral.

In addition, Ukraine, as a UN member state, must fulfill its tasks within the framework of the Sustainable Development Goals, which came into force on January 1, 2016, in which mental health is identified as a global humanitarian priority that needs to be strengthened, including by expanding mental health services. Priority ways to promote mental health, including WHO recommendations, include: early childhood interventions; child support; providing socioeconomic opportunities for women; social support for the elderly; programs targeting vulnerable populations, including minorities, indigenous peoples, migrants and people affected by conflict and natural disasters; measures to promote mental health in schools; measures to promote mental health in the workplace; strategies in the field of living conditions; violence prevention programs; community development programs; poverty reduction and social protection of the poor; anti-discrimination laws and campaigns; strengthening the rights and opportunities of people with mental disorders and care for them [1-3].

\section{Limitations of the study $\backslash$ Strengths of the study:}

The practical value of the results of our study can be used to address scientific and practical issues or problems aimed at improving the psychological health of the population, which in 
turn directly affects the economic and social development of the country.

\section{Conclusions (and Future Work)}

Thus, the state of mental health of the population of Ukraine is unsatisfactory, in addition, there is a certain lack of both human and financial resources, there is no National Policy on Mental Health. The field of mental health needs to be reformed, the role of hospitals to be reduced and the primary health care to be strengthened, and universal access to mental health services to be guaranteed. If we talk about concrete steps to improve the mental health of the population of Ukraine with a view to the future strengthening of our state, given its current state and trends, all the events taking place in Ukrainian society, of course, without proper relevant national legislation and policy mental health with the creation of a functional system of public health, where mental health should occupy one of the leading places, the country can not do. Otherwise, mental health will deteriorate shortly, morbidity and prevalence will increase not only in mental and behavioral disorders, but also other classes of illness, mortality, suicide, and then you should not expect to increase life expectancy. Also, the state of mental health of the population requires the development and adoption of the State Program for Mental Health of the Population of Ukraine, which should be comprehensive and multisectoral with clear objectives for each industry within their competence.

\section{Conflict of interest}

The author declares that she has no conflict of interests.

\section{References}

Kompleksny plan deystviy v oblasti psikhicheskogo zdorov'ya na 2013-2020 gg. [Electronic resource]. - Geneva: VOZ, 2013. Access mode: http://apps. who.int/gb/ebwha/pdf files/WHA66/ A66_R8-ru.pdf?ua =1. - Title from screen.

Integrating mental health into primary care: a global perspective [Electronic resource]. Geneva: WHO and World Organization of
Family Doctors, 2008. - Access mode: http://www.who.int/mental_health/policy/servic es/ integratingmhintoprimarycare/en. - Title from screen.

Movement for Global Mental Health. Position Statement on mental health in the post-2015 development agenda 2013 [Electronic resource]. - - Access mode: http://www.globalmentalhealth.org/sites/defaul t/files/MGMH\%20Position\%20 Statement_Post2015\%20Development\%20Agenda.pdf. - Title from screen

No health without public mental health - the case for action [Electronic resource], - London: Royal College of Psychiatrists, 2010. - Access mode: http://www.rcpsych.ac.uk/pdf/PSO4_2010.pdf. - Title from screen.

Romash, I. R., Vynnyk, M.I. (2019) Dynamics of indicators of social functioning in case of metabolic syndrome in patients with paranoid schizophrenia on the background of atypical neuroleptic agents application and improvement comorbidity. Art of medicine. 4(12): 102-9.

Romash, I., Romash, I., Barbanova, J., \& Barbanova, T. (2020). Psychological, ethical and deontological needs of the patients. Mental Health: Global Challenges Journal, 4(2), 64-66. https://doi.org/10.32437/mhgcj.v4i2.98

STEPS optional module: mental health/suicide [Electronic resource]. - Geneva: WHO, 2014. Access mode: http://www.who.int/chp/steps/riskfactor/module s/en/. - Title from screen.

The public health effect of economic crises and alternative policy responses in Europe: an empirical analysis / D. Stuckler [et al.] // Lancet. - 2009. - Vol. 374. - P. 315-323.

WHO methods and data sources for global causes of death 2000-2012. Global Health Estimates Technical Paper WHO/HIS/HSI/GHE/2014.7 [Electronic resource]. - Geneva: WHO, 2014. Access mode: http://www.who.int/healthinfo/global_burden_d isease/estimates/en/indexl.html. - ${ }^{-}$Title from screen.

WHO mortality database documentation: 1 May 2013 update [Electronic resource]. - Geneva: WHO, 2013. - Access mode: http://www.who.int/healthinfo/statistics/mortality _rawdata/en/. - Title from screen. 